\title{
CLOSTRIDIUM PUTRIFICUM
}

\author{
II. MORPHOLOGICAL, CULTURAL AND BIOCHEMICAL STUDY
}

GEORGE F. REDDISH AND LEO F. RETTGER

From the Sheffield Laboratory of Bacteriology, Yale University

Received for publication October 12, 1922

Interest in this peculiar but extremely important organism has increased within the past few years. Since Sturges and Rettger (1919) brought out again the outstanding features of this anaerobe, among them that of delayed development in pure culture, investigators have expressed widely different views. An example of the uncertainty concerning the entity of the organism in question is given by the British Medical Research Committee. In their first report on the classification and study of the anaerobes found in war wounds (Special Report Series, No. 12, 1917) certain cultural reactions attributed to it are given rather fully and there is every reason to assume that the committee at that time believed in the existence of a definite species which they were calling Bacillus putrificus. Later (1919) in their Special Report Series, No. 39., they do not make reference to it as a distinct species, but infer that "many of the cultures of $B$. putrificus, so-called, are really mixtures of $B$. cochlearius or B. tertius with B. sporogenes." They make no effort to list the cultural characters of the organism, and simply offer a short review of the work of previous investigators, which does not identify it in any way as a distinct species. The Lister Institute (London) does not list cultures of $C$. putrificum in its National Collection of Type Cultures (1922) and the writers were unable to procure from them any cultures of this organism for comparative studies.

Hall has, in a way, shown equal uncertainty in regard to the identity of $C$. putrificum. In the differential key to the sporulat- 
ing obligate anaerobes given in Jordan's General Bacteriology, this key being taken from some of Hall's unpublished data, Jordan puts C. putrificum in a group separate from C. cochlearius, The basis of differentiation is a very fundamental one, that of liquefaction of coagulated albumen and blackening of brain. Following close upon the publication of this classification scheme, however, Hall (1922) specifically states that his studies show that C. putrificum and C. cochlearius are identical. Hall, in the latter work at least, was evidently working with pure C. putrificum, but the descriptions are incomplete and in some respects erroneous. This is especially true regarding growth in milk, in which he reports no visible action. The description of $C$. cochlearius given by the British investigators is very much at variance with that suggested by Hall, the Research Committee claiming it to be identical with $C$. putrificum. The writers made a preliminary examination of the type strain of $C$. cochlearius received from the Lister Institute and found it to correspond to the description given in the British Report No. 39, and to be very unlike $C$. putrificum.

It must be admitted that many of the investigators working with this anaerobe have made use of impure cultures, and often have not had the real C. putrificum in the cultures described. The writers make no original claims as to the use of pure culture: they are interested here merely in defending the specific entity of this anaerobe, and wish to offer complete proof to substantiate their point.

The bacillus of Bienstock is an anaerobe which has constant characters and which has been described a number of times in undoubted pure culture, but each time quite incompletely. Since Bienstock's original cultures were impure, his first descriptions (Bienstock, 1894, 1899, and 1901) are worthless, except in one particular: it is certain, from his descriptions, that he had reference to an anaerobe having round, terminal spores, and that this mixture of organisms caused putrefactive decomposition of meat. Tissier and Martelly (1902) were evidently working with pure cultures, for they emphasize the inability of C. putrificum to attack sugars, even glucose, except very slightly 
and with the production of such small amounts of acid that the medium never becomes distinctly acid. This characteristic was confirmed by Rodella (1905) and also by Bienstock himself a year later (Bienstock, 1906). Distaso (1911) specifically brings out the characters of $C$. putrificum as given by Bienstock in 1906 and designates his various strains as belonging to the tetanus group, the round, terminal-spore group. Distaso, however, described two species, one of which is the true $C$. putrificum, while the other resembles in some respects both C. putrificum and "B. paraputrificum" (Bienstock). His B. putrificus-filamentosus has the specific properties claimed by Bienstock, and approaches in almost every detail the strains isolated by Sturges. His description, however, is incomplete, and is not sufficient to establish the specificity of the organism.

On the other hand, a very large number of workers have described cultures which are undoubtedly entirely different from the type strain of Bienstock. Among these may be mentioned Metchnikoff (1908), Aschoff (1917), Medical Research Committee (1917 and 1919), Kendall, Day and Walker (1922) and Kahn (1922). The misunderstanding concerning this muchbuffeted organism has been due in a large measure to the meagre descriptions given in the literature. Hall's work (Hall, 1922) not only is incomplete, but there are some errors which would certainly complicate identification if allowed to stand in the present form. The writers (1921) in a preliminary paper, attempted to point out the true characters of $C$. putrificum and later (1922) published such of their data as would establish the specific entity of the organism. The need for a complete tabulation of the morphological and cultural characters is yet felt. In the present work these are given detailed consideration. Biochemical studies of the action of the organism on peptone and glucose are included to support the qualitative cultural observations. Strains of C. putrificum isolated by Sturges were used in this study.

For the sake of clearness, the exact technique employed will be given. This feature is often neglected and the reader has too little information upon which to make comparative studies. 
Only ordinary laboratory media were used and the simplest technique employed. The composition of the media and the methods used will be given under each separate heading, or references cited which furnish the particular information.

\section{MORPHOLOGY}

The morphology of $C$. putrificum may be said to be characteristic. At least it differs very considerably from the other common anaerobes, with the possible exception of Bienstock's " $B$. paraputrificus." It is a long, slender rod, quite often curved, and in old cultures frequently occurs in long filaments. It is much more slender than the other anaerobes, being generally from 0.5 to $0.7 \mu$ broad and from 7.0 to $8.0 \mu$ long. There are often shorter forms, but these are not the common type. The spore is round and strictly terminal, and very large in proportion to the rod (See Reddish and Rettger, 1922, plate I, fig. 1). In egg-meat medium (see Rettger, 1906), in which the organism grows and preserves its viability particularly well, and in which our observations as to morphology were made most frequently, spores are not to be seen until about the tenth day or after. It may require two or three weeks for the typical spores to appear in appreciable numbers in this medium. The appearance of spores accompanies the beginning of apparent digestion of the meat. The spores remain in the rods for several days after they are first observed. At this stage they are present in large numbers. Hall (1922) apparently failed to note numerous spores in any of his cultures. This may have been due to his using a less favorable medium or not allowing sufficient time to elapse before the examinations were made. No spores have been observed by us on glucose agar and in glucose broth, although no persistent efforts were made to demonstrate their presence in these media.

C. putrificum is weakly Gram-positive, even in young cultures, and may be said to be on the border line between Gram-positive and Gram-negative. It is almost uniformly Gram-negative in old cultures. It stains well with the ordinary aniline dyes. In studying the staining property, various kinds of media were used, 
but cultures in egg-meat medium have proved in our hands to be most reliable for this purpose.

Relatively young egg-meat cultures are actively motile, and motility is not completely lost during sporulation.

\section{COLONY FORM}

Surface colonies on glucose agar (1 per cent glucose, 1.6 per cent agar, 1 per cent Difco peptone, and 0.5 per cent Liebig's beef extract $)^{1}$ even after prolonged incubation are small, delicate and almost transparent. The edge is irregularly, but not deeply dented; there are no outgrowths and no apparant fringe. The structure appears to be somewhat granular, but not coarse. (See Reddish and Rettger, 1922, fig. 2). The aid of a hand lens is necessary in order to see the colonies distinctly, since they are by far the most delicate formed by any of the anaerobes studied by the writers. At least three days are required for the colonies to show any appreciable development.

Depth colonies in glucose agar tubes $(1$ per cent glucose in 1 per cent nutrient agar) do not appear until the third of fourth day, and then they are mostly in the extreme lower portion of the tube. For the study of deep colonies, inoculation was made at the surface of the medium with a pipet, using a plain broth culture of the organism, the mixing being accomplished by rolling the tube between the hands; the tubes were incubated aerobically. Apparently the conditions in deep agar tubes favor rapid development better than surface cultivation. The development of colonies in the deeper portion of the medium only signifies the strict anaerobic conditions required. The nucleus of the depth colony is dense, and there are fine, but not long, hair-like radiations from the central portion. Because of the indistinctness of the depth colonies, sharp observations could not be made.

1 Plates poured with a thick layer of this medium were allowed to dry, inverted, at $37^{\circ} \mathrm{C}$. over night and then streaked with a bent glass rod from a saline suspension of an egg-meat culture of the organism. Incubation was at $37^{\circ} \mathrm{C}$. for three and for ten days under strictly anaerobic conditions. The time allowed for incubation before removal for description was ten days. 


\section{CULTURAL CHARACTERS}

Egg-meat. Freshly sterilized egg-meat medium was cooled quickly after sterilization, inoculated immediately from ten to fourteen day egg-meat cultures of the organism, and incubated aerobically at $37^{\circ} \mathrm{C}$. There was little change, aside from a slight turbidity, until a week to ten days after inoculation, depending upon the amount of inoculum used. By this time there is usually slight softening of the solid matter and the meat and egg particles become finer. This disintegration is at first most apparent in the upper portion of the medium, but latter progresses into the lower layers. Reddening of the meat has by this time become very pronounced. By the end of the second week there is some decrease in the bulk of the solid matter and digestion is very apparent; this pronounced change is accompanied by the evolution of the foul odors that are characteristic of real putrefaction. Because of the evaporation of the liquid resulting from the long incubation, there is never a very deep layer of liquid over the undigested residue, such as is noted in egg-meat cultures of $C$. sporogenes. The meat is darkened only slightly, the deep red color being dominant throughout the digestion. Only when the meat has become entirely decomposed is there definite browning; the residue in old dried cultures is, however, almost black, but this change does not take place until after several months. There is no apparent gas production at any time. The digestion of the egg-meat is never rapid, and the evaporation of the supernatant liquid almost keeps pace with it.

Milk. Deep tubes of freshly sterilized skim milk were cooled quickly in water and then inoculated with one loopful of an eggmeat culture of the organism, ${ }^{2}$ after which sterile melted paraffin was added to form a seal about half an inch in thickness. The tubes were incubated at $34^{\circ} \mathrm{C}$, and not $37^{\circ} \mathrm{C}$. because the paraffin softened at the latter temperature. Under these conditions there is slow precipitation of the casein and later almost complete

\footnotetext{
2 A loopful of a ten to fourteen day meat culture is as a rule large, for the solid particles cling to the loop in the form of lumps of partly digested meat, in which much enzyme is carried.
} 
digestion. The time required for this action varies with the inoculum, but more definitely with the age of the culture from which inoculation was made. This is illustrated by the following experiment. Four freshly sterilized deep tubes of milk were inoculated with a large loopful of six-weeks old egg-meat cultures of four strains of C. putrificum. Four other deep tubes of freshly sterilized milk were inoculated with a large loop of twenty-four-hour egg-meat cultures of these same strains.' All eight tubes were sealed with sterile melted paraffin and incubated at $34^{\circ} \mathrm{C}$. The four tubes which were inoculated with the old (digested) cultures showed slight digestion at the end of twentyfour hours, and practically complete digestion of the casein within four days. On the other hand, the tubes inoculated with the young cultures did not show any change until the twelfth to fifteenth day, when there was some digestion of the slightly precipitated casein. One of the tubes did not show any signs of growth for four weeks, after which time there was slow digestion of the casein. In all of the last four tubes the digestion took place slowly. The rapidity of the action in the first set was probably due to the preformed enzymes carried over. ${ }^{3}$

Broth. Ordinary plain nutrient broth made with beef extract was inoculated with a large loop of a three to four weeks old egg-meat culture and covered with sterile melted paraffin. Tubes without paraffin were placed for comparison in an anaerobic jar and both sets were incubated at $34^{\circ} \mathrm{C}$. The growth after two days was slight to fair. In glucose broth the growth is little if any better. The turbidity is never sufficiently great to cause at most more than a very slight sediment.

Gelatin. When gelatin is inoculated with a three to four weeks old culture, rapid liquefaction takes place (one to five days), but when young cultures are used as inoculum the liquefaction is correspondingly slow, and may require from two to three weeks. Liquefaction progresses at about the same rate in plain and glucose gelatin. ${ }^{4}$

\footnotetext{
3 This may account for the varying results claimed with this medium. Some investigators report rapid digestion of casein, while others claim that there is no apparent action at all in milk.

- Deep, narrow tubes incubated aerobically.
} 
Loeffler's serum. Ordinary Loeffler's blood serum used for growing Coryneb. diphtheriae was employed in place of the inspissated horse serum recommended by certain English investigators. Growth was observed after three days' incubation at $37^{\circ} \mathrm{C}$. in an anaerobic jar, following heavy inoculation with old cultures. Digestion did not take place completely until after five days.

\section{BIOCHEMICAL REACTIONS}

Fermentation tests. The following substances were used in testing for acid and gas:

Pentoses: xylose and arabinose.

Hexoses: glucose, levulose, galactose and mannose.

Disaccharides: lactose, sucrose, maltose and trehalose.

Trisaccharides: raffinose and melezitose.

Polysaccharides: soluble starch, dextrin, glycogen and inulin.

Methyl pentose: rhamnose.

Glucosides: salicin, amygdalin, esculin and inosite.

Alcohols: mannitol, glycerol, erythritol, dulcitol and sorbitol.

These were used in plain nutrient 1 per cent agar, adjusted to $\mathrm{pH} 7.0$ before sterilization. The test substances were added to make a 0.5 per cent solution and the medium filled into tubes which had been previously sterilized, thus allowing for a shorter sterilization period. The tubes were sterilized at 15 pounds for ten minutes, cooled quickly to $45^{\circ} \mathrm{C}$. and inoculated as soon as possible. Inoculations were made with a 1 to 1 suspension of a twenty-four hour plain broth culture of the organism, 0.5 cc. being added at the surface of the medium. The tubes were then rolled vigorously between the hands to insure thorough distribution of the organisms, and incubated aerobically at $37^{\circ} \mathrm{C}$. A control plain agar tube was also included. None of the test substances were apparently fermented. At least there was no visible gas production and tests for acid by the brom-thymolblue method were negative. In testing for acid the indicator was added to the melted culture after a week's incubation. Colonies were easily visible by the third or fourth day in all of 
these media. As is shown below, glucose is probably feebly attacked, but not enough to yield acid in sufficient amount to show in the brom-thymol-blue test as used above.

Glucose-consuming power. One per cent glucose broth was used for determining quantitatively the amount of glucose consumed by $C$. putrificum. The broth was filled into large tubes, 20 cc. per tube, sterilized and cooled quickly before inoculation with 0.5 cc. of a twenty-four hour plain broth culture. ${ }^{5}$ Six tubes were so inoculated and quickly placed in six separate anaerobic jars. In this way it was possible to open one tube at a time without disturbing the anaerobic conditions under which the others were kept. Quantitative determinations of glucose were made by the method of Benedict (see Cole's Practical Physiological Chemistry, 1919, p. 127). Readings were made at the end of 12 hours, 36 hours, 60 hours, 7 days and 14 days. The hydrogen ion concentration of the cultures was also determined at the same time.

Glucose is attacked but slightly, and not enough to be considered as indicative of definite saccharolytic property on the part of the organism. A loss of only 0.1 per cent glucose is recorded (See Reddish and Rettger, 1922, chart 1). Allowing for experimental error, the amount consumed may be even less. At least, the ability of the organism to consume this sugar is not an outstanding or important feature of its metabolism. The hydrogen ion changes did not keep pace with the glucose reduction, due to the simultaneous production of alkali. The $\mathrm{pH}$ dropped from 7.3 to 6.6 , but the degree of acidity is not such as would be readily measurable in melted agar cultures by any of the tests now employed, as noted above. The amount of chemically determined glucose was reduced from 0.727 to 0.625 per cent in fourteen days at $37^{\circ} \mathrm{C}$. C. sporogenes, on the other hand, reduced the glucose from 0.727 to 0.385 per cent in fourteen days. C. tetani consumed more dextrose than did C. putrificum, reducing it from 0.727 to 0.541 per cent in fourteen days. Therefore, relatively speaking, at least, $C$. putrificum

\footnotetext{
- The use of a twenty-four hour seed culture was made possible by making a heavy inoculum in the original plain broth.
} 
is in a class by itself so far as its action on glucose is concerned. For all practical purposes, it may be considered non-saccharolytic.

Peptolytic property. For determining the degree of peptolytic action on commercial peptone, ordinary plain broth, in $35 \mathrm{cc}$. amounts in large tubes, was inoculated with $1 \mathrm{cc}$. of a twenty-four hour plain broth culture. The inoculation was made immediately after sterilization and cooling, and the tubes were placed in separate jars and put under anaerobic conditions, the number of tubes and jars being sufficient to allow for determinations at the end of 12 hours, 36 hours, 60 hours, 7 days and 14 days, without disturbing the unused tubes. The following tests for following the destruction of the peptone were used in the present studies: (1) quantitative biuret, (2) Sörensen, (3) ammonia, and (4) amino-acids. The biuret test is essentially that employed by Vernon (1903). A modified Sörensen test, ${ }^{6}$ as used by Kendall and Walker (1915) and others was used for determining approximately the ammonia and amino-acids present. The use of the ammonia test has been widely employed both in this country and abroad. The test as used in this work makes use of the iodine-thiosulphate titration (see Sutton's Volumetric Analysis, 8th edition, 1900). Van Slyke's modification of Folin's test was employed for liberating the ammonia in the broth cultures, the gas being collected in acid solution of known strength. The iodine-thiosulphate method of titrating was used because of its greater accuracy. The amino-acids were determined by the micro-method of Van Slyke (1913-1914, 1915).

The albumoses peptone, and higher polypeptids are attacked very little before the third day, but by the seventh day there is considerable change. There is, by this time, a great decrease in the biuret-giving substances, with a consequent increase in the ammonia and Sörensen figures. After one week's incubation the ammonia and Sörensen figures increase only slightly over the seven day reading and there is practically no further destruc-

- In the Sörensen test $5 \mathrm{cc}$. of neutral formaldehyde were employed and the titration with $\frac{\mathrm{N}}{20} \mathrm{NaOH}$ made immediately after the formaldehyde was stirred into the solution. 
tion of the biuret-giving substances. The delayed action on peptone is not surprising, because of the general tendencies of the organism toward poor development in pure culture in the early stages of growth. Since peptone is more easily attacked than the more complex protein of meat, the changes noted as taking place in seven days are comparable to those taking place in meat after a longer period. Another index of the destructive activity of the organism and its enzymes on egg-meat and proteins in general is the almost complete conversion of the aminonitrogen into ammonia-nitrogen in the experiments. (see Chart 2 , in the previous paper, 1922).

Pathogenicity. A 1 to 10 suspension of a two weeks old eggmeat culture when injected intraperitoneally causes no changes whatever in the condition of the animals tested (white mice and guinea pigs).

Although the media and methods used in this study have been very simple, sufficient data are given to point out clearly the essential features of this peculiar organism. The characteristics as brought out here coincide with certain outstanding features ascribed to it by Bienstock. It is hoped that in the present work, the characteristics exhibited and described may be of material use in placing the organism in its proper group in the classification of anaerobes, and also offer a more or less complete method of identification with the kinds of media most used in this country. A definite effort has been made to employ only such media as can be procured and made easily.

According to the work here presented, C. putrificum is not only a definite and distinct species, but should be placed in a group of its own among the known anaerobes. It is proteolytic, peptolytic and at most only very slightly saccharolytic.

\section{REFERENCES}

Ascrorr, L. 1917 Ueber bakteriologische Befunde bei den Gasphlegmonen. Deutsche med. Wchnschr., 43, 1468-1469.

Bienstock, B. 1884 Ueber die Bakterien der Fäces. Ztschr. f. klin. Med., $8,1$.

Bienstock, B. 1899 Untersuchungen uber die Aetiologie der Eiweissfäulnis. Arch. f. Hyg., 36, 335-389. 
Birnstock, B. 1901 Milchfäulnis, Verhinderung der Fäulnis durch Milch. Arch. f. Hyg., 39, 390-427.

Bienstock, B. 1906 Bacillus putrificus. Ann. de l'Inst. Pasteur, 20, 407-415.

Coxs, S. W. 1919 Practical Physiological Chemistry. 5th edition. London.

Distaso, A. 1911 Sur les microbes proteolytiques de la flore intestinale de l'homme et des animaux. Cent. f. Bakteriol., Orig., 59, 97-103.

HALL, I. C. 1922 Differentiation and identification of the sporulating anaerobes. J. Inf. Dis., 30, 445-504.

Jordan, A. O. 1922 General Bacteriology. 7th edition. Phila.

KAHN, M. C. 1922 A cultural study of anaerobic spore-bearing bacteria with strains isolated by the Barber single cell technique. Jour. Med. Res., 43, 155-206.

Kendali, A. I., Dax, A. A., ANd Walker, A. W. 1922 Studies in bacterial metabolism. XLIV-LVI. J. Inf. Dis., 30, 141-210.

Medical Research Committee 1917 National Health Insurance. Special Report Series 12. The classification and study of the anaerobic bacteria of war wounds. London. pp. 74.

Medical Research Committee 1919 National Health Insurance. Special Report Series 39. Reports of the committee upon anaerobic bacteria and infection. London. pp. 182.

Metchnikoff, E. 1908 Etudes sur la flore intestinale. Ann. de l'Inst. Pasteur, 22, 929-955.

Reddish, G. F., AND RetTGer, L. F. 1921 Clostridium putrificum, a distinct species. Proc. Soc. Amer. Bact., 23rd Ann. Meeting, Philadelphia. Abstr. Bact., 6, 9.

Reddish, G. F., AND RetTGer, L. F. 1922 Clostridium putrificum, a distinct species. Jour. Bact., 7, 505-510.

Rettaer, L. F. 1906 Studies on putrefaction. J. Biol. Chem., 2, 71-86.

Rodella, A. 1905 Sur la differenciation du "Bacillus putrificus" (Bienstock). Ann. de 1'Inst. Pasteur, 19, 804-811.

Sutron, F. 1900 Volumetric Analysis. 8th edition. London. pp. 640.

Vernon, H. M. 1903 Jour. Physiol., 30, 330. 